\title{
Spatial Variations in Exclusionary Criteria from Online Rental Advertisements
}

Forthcoming in The Professional Geographer

Providence Adu

Department of Geography \& Earth Sciences

University of North Carolina at Charlotte

Charlotte, NC 28223

padu@uncc.edu

Elizabeth C. Delmelle*

Department of Geography \& Earth Sciences

University of North Carolina at Charlotte

Charlotte, NC 28223

edelmell@uncc.edu

*corresponding author 


\title{
Spatial Variations in Exclusionary Criteria from Online Rental Advertisements
}

\begin{abstract}
While the Fair Housing Act prohibits discrimination in the rental housing market on the basis of race, color, or religion, there exist ample opportunities for landlords to restrict their rental units to individuals with various backgrounds using exclusionary screening practices. These criteria, such as minimum credit scores, criminal history, source of income, or prior evictions, for instance, are often correlated with race and thus hold the potential to perpetuate spatial patterns of racial and income segregation. In this article, we analyzed online rental listings from Zillow and Craigslist in a case study of Charlotte, North Carolina to examine the proliferation and spatial variation in exclusionary criteria by neighborhood race and income. Overall, we found criminal background, credit score, housing voucher, eviction, and minimum income restrictions to be greater in poorer and minority neighborhoods. However, when distinguishing by platform, we found the presence of corporate landlords, who did not advertise on Craigslist, to be a significant driver of these results. Corporate landlords represented nearly 60 percent of advertisements on Zillow and were more common in poorer and minority neighborhoods - they also systematically included nearly all restrictions. Craigslist, by contrast, had fewer criteria that correlated with race and income.
\end{abstract}

Keywords: Housing Discrimination; Natural Language Processing; Online Rental Listings; Spatial Analysis; Web-scraping

\section{Introduction}

More than 30 years have passed since the 1986 extension of the Fair Housing Act, meant to strengthen its 1968 predecessor, made discrimination in the housing market on the basis of race, color, religion, disability, or sexual orientation illegal. Despite these laws, discrimination remains a widespread practice (Schwemm, 2006; Hanson \& Hawley, 2011), contributing to the perpetuation of segregation by race and income observed throughout many US cities (Rosen, 2014). While a large body of literature has focused on racial discrimination in the rental housing market including the motivation and mechanisms used by landlords to discriminate (e.g. Ondrich et al., 1999; Hanson \& Hawley, 2011; Hanson \& Hawley, 2014), other, less explicit, and often legal forms of discrimination exist that serve to restrict housing options and contribute to the spatial reproduction of poverty and inequality. Many of these restrictions, or exclusionary criteria, are 
aimed at predominantly lower-income and minority renters with discredited backgrounds such as criminal backgrounds, prior evictions, poor or no credit history, those possessing housing vouchers, or not meeting a minimum income requirement, for example (Rosen, 2021; Reosti, 2020).

To date, there has been limited systematic examination of the extent to which exclusionary screening processes are present in the rental housing market, and how these practices vary spatially, according to the racial or income makeup of a city. This is likely due to the relative lack of data on rental housing markets in general. However, the movement towards online rental platforms and data science methods have enabled some recent breakthroughs in quantifying elements of the rental housing market (Boeing \& Waddell 2017; Boeing 2020; Costa et al., 2021; Hess et al., 2021).

In this article, we build upon this progress and develop a method for analyzing the extent to which categorial exclusionary criteria are present in rental listings obtained from Zillow and Craigslist, in a case study of listings in the fast-growing, competitive housing market of Charlotte, North Carolina. We apply natural language processing techniques to facilitate an analysis of terms that exclude groups of potential renters from obtaining housing (e.g. no criminal backgrounds, no prior evictions, minimum incomes, minimum credit scores, etc.) and we compare the pervasiveness of these terms by the race and income at the neighborhood level. This analysis sheds light onto some of the struggles associated with finding housing, especially in a competitive market such as Charlotte, and adds to the growing literature onto the barriers faced by low-income and minority residents in securing housing (Rosen, 2021).

\section{Background}

\subsection{Discrimination in Rental Housing Market}


From a legal standpoint, discrimination in housing occurs when an individual is denied access to housing due to their race, color, national origin, familial status, religion, ethnicity, disability, or sexual orientation. The 1968 Fair Housing Act made it illegal for real estate agents or landlords to explicitly discriminate according to these characteristics. Nonetheless, there exist techniques for circumventing this law that serve to prevent a person from residing in a home or neighborhood of his or her choosing. Research has demonstrated that discrimination, or the unequal treatment of otherwise equally qualified individuals because of their association with some group - remains a widespread practice by landlords (Ondrich et al., 1999). The implications of these are far reaching - individuals are less able to obtain access to the neighborhood and its associated opportunities of their choosing, potentially diminishing their economic and educational prospects. When discrimination occurs systematically across racial or socioeconomic groups, patterns of inequality and segregation are perpetuated (Langowski et al., 2020).

With respect to the rental housing market, landlords may be motivated to be 'discriminant' when seeking out tenants for their properties - they would ideally prefer to rent to an individual or household who appears least likely to miss a rent payment, to be disruptive, to cause damage to their property, or to break a lease, for example (Hulchanski, 1994). To minimize the possibility of leasing to an 'inferior tenant' (Galster, 1992), landlords often enact a type of heuristic to restrict their rental units to individuals belonging to a group whose collective characteristics are correlated with being a bad tenant. This practice is referred to as statistical discrimination - where an individual is judged based on the average of the group it belongs to, rather than the characteristics of him or herself (Phelps, 1972; Hulchanski, 1994). In an increasingly digital rental market, statistical discrimination is often manifest through algorithmic proxies that screen applicants based on a set of exclusionary criteria (Rosen et al., 2021). These seemingly objective criteria are 
designed to fall within legal boundaries and are therefore more regularly used by larger and corporate landlords (Decker, 2021; Rosen et al., 2021). In our analysis, we use the more encompassing, categorical exclusionary criteria term as some of these restrictions are not rooted in statistical association, but based more on preference or perceptions of groups of people.

One example of statistical discrimination is a minimum income requirement - on average, those with lower incomes might be more likely to miss rent payments, but that does not speak to the unique circumstance of each individual. Housing voucher holders are often stigmatized and perceived as high risk, though in reality their rental payments are guaranteed to be on-time and may therefore be desirable in lower-income submarkets (Rosen, 2014). Research has shown that higher-rent landlords are more likely to avoid voucher holders because of their associated stigma (Phillips, 2017). Consequently, voucher holders tend to be concentrated in poorer neighborhoods with more minority residents than non-voucher holders (Deluca et al., 2013; Metzger, 2014). In places where source of income discrimination is illegal, the location of housing voucher recipients is more dispersed (Freeman, 2012; Metzger, 2014; Tighe et al., 2014). Further examples of exclusionary criteria used by landlords include criminal backgrounds (Clark, 2007), previous rental history including any prior evictions (Porton et al., 2020), and minimum credit scores (Reosti, 2020).

The restriction of housing options to those with discredited backgrounds has been shown to induce significant mental and monetary costs with respect to the housing search process (Reosti, 2021). As a result, they are often relegated to substandard housing in disadvantaged neighborhoods, thus perpetuating their cycle of disadvantage. More broadly, the use of exclusionary criteria ultimately shapes residential sorting patterns by inserting the desires of landlords into the location choice process. In the rental housing market, these decisions are far 
from operating in a way that tenants maximize their preferences for homes and neighborhoods according to their budget. Rather, landlords select tenants that meet their desired criteria (Evans et al., 2019). The more competitive the housing market, the greater power a landlord has in filtering applicants. Recently, the presence of corporate landlords in cities has grown rapidly because of the mortgage crisis, as they purchased large quantities of foreclosed or real-estate owned properties concentrated in lower-income and minority neighborhoods, or those areas that were prime targets for predatory mortgages (Fields, 2018). These landlords have been shown to largely rely on rigid algorithmic processes to screen or exclude potential tenants, as compared to smaller landlords who use more seemingly subjective criteria, or gut feelings (Decker et al., 2021; Rosen et al., 2021).

\subsection{Discrimination in Digital Rental Platforms}

There exist complexities when it comes to regulating discrimination on digital rental platforms like Realtor.com, Apartment.com, Zillow, and Craigslist. Whereas the Federal Fair Housing Act makes it illegal to print, publish or advertise listings with discriminatory languages, federal policies like the Communication Decency Act of 1996 protects digital housing platforms from liability of user generated content (Oliveri, 2009). This contradiction in the Federal Fair Housing Act and the Communication Decency Act means that discriminatory advertisements find their way onto digital rental platforms.

Recently, several studies have used web-scraping and text analysis techniques to analyze online rental listings. This work has shown that rental advertisement language differs in predominantly White versus minority neighborhoods. In the case of Seattle, rental advertisements scraped from Craigslist showed that in White neighborhoods, the history and culture of the neighborhood were emphasized, while in non-White neighborhoods, terms emphasized the availability of bus transit and fewer neighborhood amenities (Kennedy et al., 
2021). Delmelle and Nilsson (2021) reached similar conclusions in the case of single-family property listings in Charlotte, North Carolina: housing advertisements from neighborhoods with a recent influx of White residents highlighted urban amenities and the name of the neighborhood, while in neighborhoods with predominantly Black homebuyers, schools were less likely to be mentioned. In an analysis of Craigslist rental listings, Besbris et al. (2021) found exclusionary criteria to be more prevalent in poorer and minority neighborhoods.

Research has also revealed that online rental listings vary in their geographic distribution. Predominantly White neighborhoods have a larger share of advertised listings, suggesting that online listings and information are segregated along class and racial lines (Boeing 2020; Boeing et al., 2021; Brannon 2017). This implies that access to rental information is unequal to all individuals, making online housing markets unevenly segmented. Thus, whereas listings might not explicitly discriminate in language, where listings are advertised in a digital space contributes to discrimination as they overly represent the wealthier, educated and predominantly White communities. Furthermore, the amount of information contained in listings varies by location as it is not illegal for landlords to selectively share information on rental housing advertisements. Minorities tend to have less information when searching for properties to rent. As these discriminatory patterns persist, digital platforms risk reproducing historical patterns of residential segregation (Boeing et al., 2021). Recent research has also uncovered differences in online rental platforms. For example, Craigslist and apartments.com are used as a source for more affordable rental housing opportunities (Costa et al., 2021; Hess et al., 2021).

While this emerging stream of research has revealed differences in terms of the location of online listings and their language, there remains a gap in understanding how they may contribute to restricting certain populations from obtaining housing or neighborhoods of their choosing based 
on the stated exclusionary criteria. As online listings are often the first source of information tenants use to evaluate prospective units and neighborhoods (Krysan \& Crowder, 2017), the concentration of these criteria in particular neighborhoods could serve to steer away populations most impacted by them, those who are more often lower-income and minority, and therefore contribute to perpetuating patterns of segregation. We also examine whether differences exist between two popular platforms: Craigslist and Zillow on the prevalence and spatial variation in exclusionary criteria.

\section{Data, Geographic Scope, and Methods}

\subsection{Study Area}

The geographic scope of this research is Charlotte, North Carolina, the largest city in the state, and one of the fastest growing in the country. Charlotte is the 16th largest city in the United States, with a population of approximately 880,000 that is projected to reach 2.7 million by 2030 (US Census Bureau, 2019). Growth in the city has been characterized by strong gentrification trends towards the center city, as the city's financial and banking industries have grown, while poverty and lower-wage jobs have moved away from this core (Delmelle et al., 2020).

As Charlotte rapidly grows, there is pressure on its housing market as demand has outpaced supply, resulting in rising rental and owner-occupied housing prices. Consequently, the current average and median rental and real estate prices have reached an all-time high (Childress Klein Center for Real Estate, 2020). Therefore, the city has explored multiple policy interventions. For example, the city's latest 2040 comprehensive plan recommended modifying its current zoning to allow for more affordable housing options (Charlotte 2040 comprehensive plan, 2020). Coupled with this affordable housing crisis has been the rise of corporate landlords (Portillo \& Lane, 2021) who have been noted for squeezing renters with threats of eviction and court filings (Raymond et 
al., 2016) as they advance profit seeking goals. Nationwide, the rise of corporate landlords followed the housing market crash as investors purchased large quantities of homes in foreclosure, often in areas of high poverty, or those that were targets of predatory lenders. These often out-ofstate investors have therefore turned neighborhoods that were largely owner-occupied into renteroccupied, arguably leading to neighborhood destabilization (Fields, 2018; Seymour \& Akers, 2021).

As Charlotte grapples with affordable housing crisis and homelessness in the city, there have been calls to address issues of discrimination in the housing market (Lindstrom, 2019). Apart from the standard 1968 fair housing policy against discrimination, the city has no substantive antihousing discriminatory policy, thus exposing renters to subtle discriminatory practices.

\subsection{Rental Data - Web Scraping Procedure}

We designed a Python-based web scraper to acquire rental listings from Zillow and Craigslist. The scraper was run daily between 3 March, 2021 and 17 November, 2021, capturing rental listings that were posted on both platforms. During the 260-day period, a total of 51,155 rental listings were acquired. For each rental listing, we collected the price, bedrooms, bathrooms, description text, address, zip code, neighborhood, square footage, and the URL.

\subsection{Data Cleaning}

Craigslist and Zillow do not prevent users from posting rental advertisements multiple times and they allow users to make changes or update their rental listings after they have been posted. Also, some users post their advertisements on both platforms. Because of this, there were duplicate listings in the initial set of 51,155 , so we filtered out only those that had distinct addresses. Because users frequently made small changes to their text to make their listing appear more often, filtering by both distinct address and text still resulted in a large amount of redundancy. 
We therefore opted to keep only one listing per address, including when there were multiple units in an apartment complex.

Further, since these rental listings are user generated, there were some inaccuracies in the collected sample. In some instances, home sales listings found their way into the rental listings category, and there were price outliers (rentals listed at $\$ 179,000$ or $\$ 70$, for example), or extremely high values for square footage, number of bedrooms and bathrooms. All of these outliers were removed in the cleaning process. In subsequent text cleaning steps, we removed stop words, punctuations, multiple white spaces, and weblinks, converted the text to lower case, and changed key words to their singular form, for example, 'evictions' to 'eviction' and 'felonies' to 'felony', etc.

After removing duplicates and cleaning the initial dataset, a total of 10,146 rental listings remained. These were next geocoded to a census tract and listings that fell outside of the Charlotte city limits were removed, further reducing the sample to 8616 listings. Among these, 7175 were from Zillow while 1442 listings were from Craigslist (see Table 1 for descriptive statistics on rental listings). Briefly, the Table shows that Zillow listings have a higher mean rent as compared to Craigslist, while the size of properties on Craigslist was smaller. The median monthly rent per square foot was then very similar between the two platforms. 
Table 1. Descriptive statistics of original rental listings and rental listings with unique addresses.

\begin{tabular}{llllll}
\hline $\begin{array}{l}\text { Descriptive } \\
\text { Statistics }\end{array}$ & $\begin{array}{l}\text { Original } \\
\text { Datasets }\end{array}$ & $\begin{array}{l}\text { Unique } \\
\text { Address }\end{array}$ & $\begin{array}{l}\text { Charlott } \\
\text { e } \\
\text { Listings }\end{array}$ & $\begin{array}{l}\text { Zillow } \\
\text { Listings }\end{array}$ & $\begin{array}{l}\text { Craigslist } \\
\text { Listings }\end{array}$ \\
\hline Count of listings & 51155 & 10146 & 8616 & 7175 & 1442 \\
Mean Rent & $\$ 1462$ & $\$ 1745$ & $\$ 1783$ & $\$ 1908$ & $\$ 1294$ \\
Median Rent & $\$ 1355$ & $\$ 1695.0$ & $\$ 1750$ & $\$ 1800$ & $\$ 1150$ \\
Median Square ft & $1355 \mathrm{ft}$ & $1456 \mathrm{ft}$ & $1540 \mathrm{ft}$ & $1595 \mathrm{ft}$ & $1120 \mathrm{ft}$ \\
Median Rent/square ft & $\$ 1.30$ & $\$ 1.15$ & $\$ 1.14$ & $\$ 1.13$ & $\$ 1.20$ \\
Mean Bedrooms & 2.09 & 2.82 & 2.91 & 3.0 & 2.43 \\
Mean Bathrooms & 1.65 & 1.88 & 1.91 & 1.92 & 1.84 \\
\hline
\end{tabular}

\subsection{Discriminatory language analysis}

To assess spatial variations in exclusionary criteria across the city tracts, we began by creating a list of terms and phrases that could potentially represent a barrier for individuals seeking to rent properties, especially those of lower socioeconomic status including ex-convicts, lowincome earners, and minorities. These terms were informed by the literature and refined by an initial exploration of terms in our corpus and included $^{1}$ : credit scores, credit report, credit history, housing vouchers, section 8 , proof of income, income to debt ratio, pay stubs, criminal background checks, criminal history, felony, misdemeanor, unemployment, eviction, homeowners association (HOA). For each term from our list, a column was created in our database containing the number of times for which the term appeared, enabling us to visualize the extent to which the words varied spatially for rental listings by census tract. Our initial exploratory text analysis (bi-gram modeling)

\footnotetext{
${ }^{1}$ Our exploratory text analysis included examining frequent word counts, exploratory topic modeling, and bi-gram modeling to ensure that no additional, frequently mentioned term was missed.
} 
also revealed a list of corporate landlords ${ }^{2}$ in our corpus as frequent co-occurring terms. We therefore created a list of these landlords, which we corroborated with a report from the city of Charlotte, that identified corporate landlords operating in the city via their SEC filing details. Upon further investigation, we found that these corporate landlords did not advertise on Craigslist to reduce rental fraud under their names, given that anyone can advertise freely on that platform. Paid platforms such as Zillow reduce the risk of imposters using one of these names in their advertisements. When corporate landlords advertise, they always use their company website, name, and contact information in the rental listing description, and therefore, in our analysis, we flagged listings that contained a name from our official list and these identifying tags.

\subsection{Analytical Approach}

To determine if the exclusionary criteria varied by race and income in the city, thereby acting as a potential barrier for entry into a neighborhood, we performed a simple linear regression on the share of listings in each tract containing each criterion by the share of White residents and the median household income of the tract, both obtained from the 2015-2019 American Community Survey. Because of significant multicollinearity in the race and income variables, attributed to high levels of segregation in the city (see Figure 1), we had to place these two variables in separate models. Note that our objective was to examine how these terms varied specifically with race and income and was not intended to explore all possible factors that explain their spatial variation.

\section{Results}

\footnotetext{
${ }^{2}$ We identified the following corporate landlords in our corpus: Invitation Homes, Main Street Renewal, Tricon Residential, Progress Residential, HomeRiver Group, American Homes 4 Rent, Mynd Property Management, First Key Homes LLC
} 
In our corpus of 8616 property listings, we tallied 19,460 exclusionary criteria, given that a single listing could contain multiple terms. When exclusionary criteria were not explicitly listed, a follow-up on the advertising agency website sometimes indicated that these conditions still applied even when agencies stated that they upheld 'equal housing' standards. These included conditions requiring no prior evictions, no criminal record, and a consumer credit report and public record check that "discloses the applicant's character, general reputation, personal characteristics and mode of living". This indicates that even when a listing does not explicitly state exclusionary criteria in their advertisement, they still have a potential to be a barrier at some stage during the renting process. We also found that corporate landlords, who only advertised on Zillow, systematically listed nearly all exclusionary criteria (except for HOA and Housing Voucher) in every listing. A map illustrating the spatial distribution of listings by platform and the race and income distributions across the city is shown in Figure 1. According to the Figure, the overall distribution of listings is higher in the outer ring of the city, areas of higher shares of minorities and lower incomes, avoiding the so-called 'wedge of wealth', extending south from the center city. A concentration of listings is also shown in the central business district, directly in the center of the maps - these listings are notably less prevalent on Zillow as compared to Craigslist. 


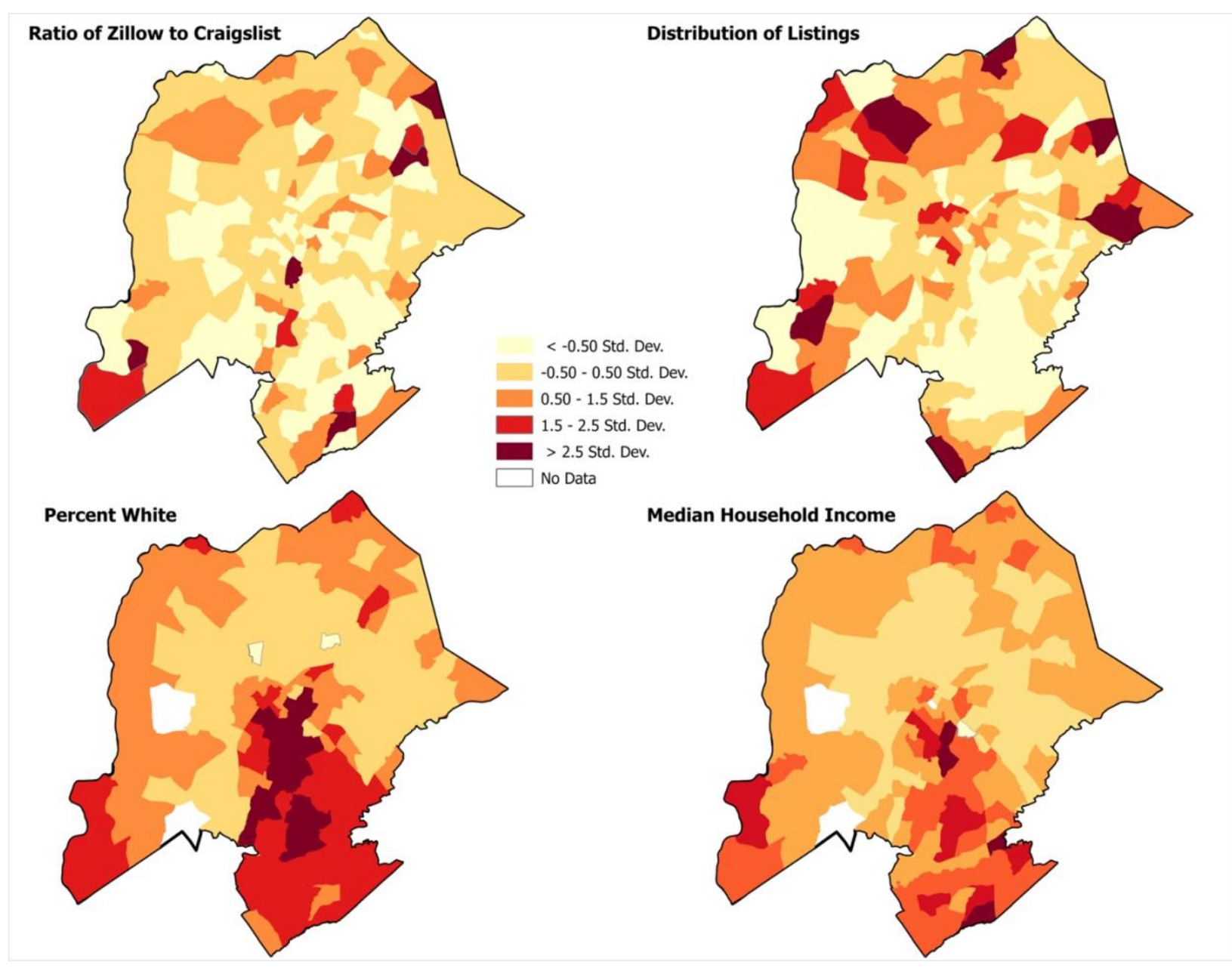

Figure 1. Spatial distribution of a) the ratio of Zillow to Craigslist listings; b) All listings; c) Percent White; d) Median Household Income in Charlotte, NC.

We now turn to the analysis of each exclusionary criteria. The spatial distribution, represented as the share of listings mentioning the criteria, normalized by the total number of listings in each tract is shown in Figure 2. As can be seen in the Figure, minimum credit scores, no criminal backgrounds, no prior evictions, and minimum income requirements are the most listed exclusionary criteria. These were most common in poorer, minority neighborhoods of the outer ring of the city which represents some of the oldest suburban or single-family neighborhoods within the broader metropolitan area. The mentioning of HOAs and housing voucher restrictions 
were much less common - largely because they were not systematically included in the corporate landlord listings; they consequently follow distinct spatial patterns.
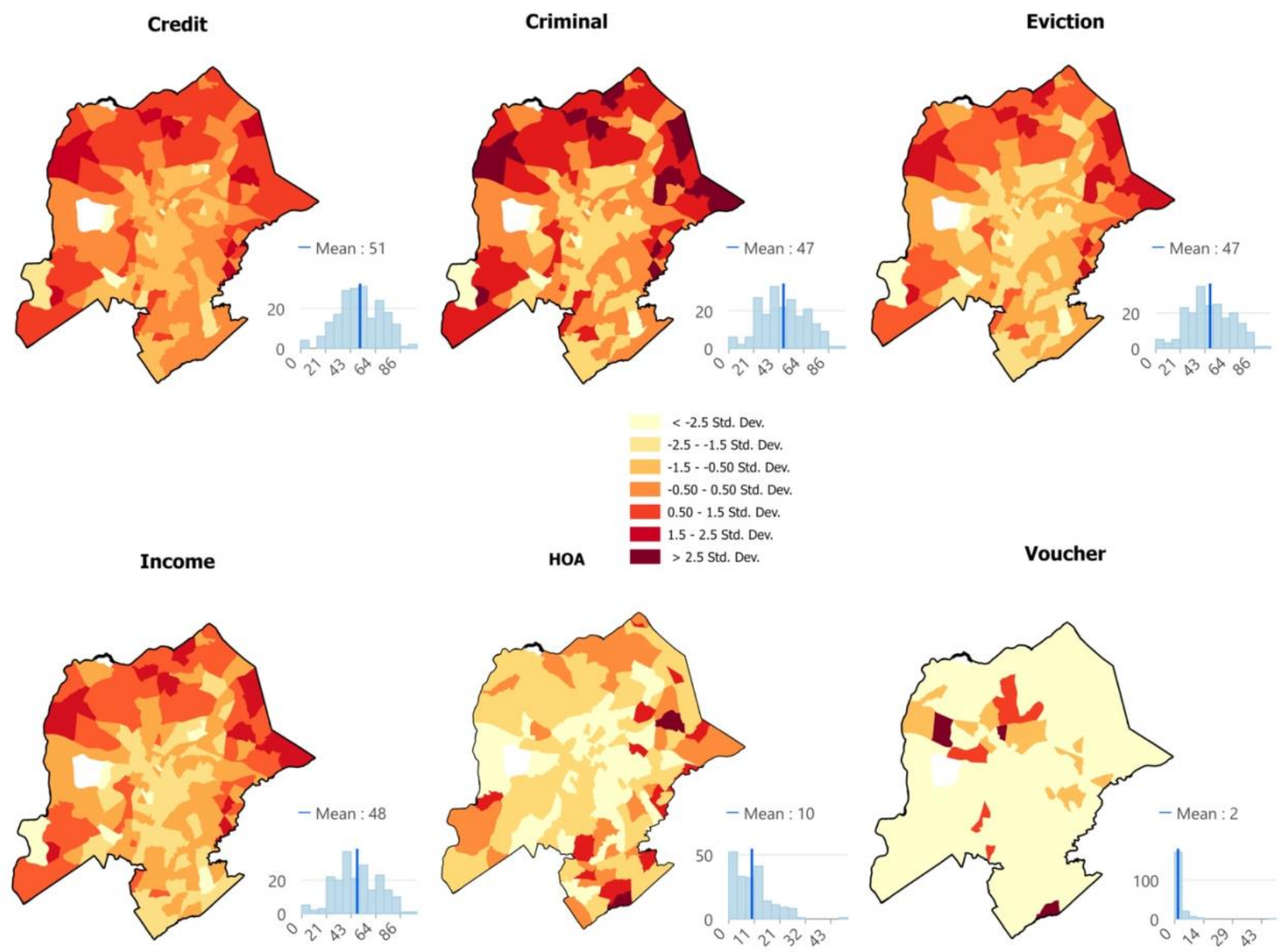

Figure 2. Spatial distribution of each exclusionary criterion in Charlotte, NC

Table 2 shows the results of our simple linear regressions with the share of each criterion and the percent White and the median household income of each tract, for all listings combined and then separated between Zillow and Craigslist. Overall, we find criminal backgrounds, credit scores, housing vouchers, evictions, and minimum income restrictions to be less common in Whiter neighborhoods, and therefore, more pervasive in minority neighborhoods. Minimum credit scores were present in nearly $50 \%$ of all listings. Corroborating the maps in Figure 2, housing 
voucher restrictions were mentioned the least frequently, explicitly stated in only $1.5 \%$ of our sample. However, the population that relies upon vouchers will typically be excluded based on minimum income restrictions alone.

Homeowners Associations (HOAs) show the opposite spatial pattern, more concentrated in Whiter and wealthier neighborhoods. While HOAs may not be as intuitively exclusionary as some of the other terms in our list, their mandatory fees - often for amenities largely catered towards wealthier and Whiter residents such as golf courses - and their additional covenants (Strahilevitz, 2006), have led researchers to reveal that HOA neighborhoods tend to be more racially segregated and affluent than nearby neighborhoods (Meltzer, 2013; Clarke \& Freedman, 2019). As is the case in most fast-growing, southern, US cities, HOAs are increasingly popular in Charlotte both in the rental and mortgage housing market. HOAs are small neighborhood groups who fight for and maintain the interest of its members such as maintaining safety and security of their respective neighborhoods. Historically, HOAs are known for perpetuating discriminatory acts in housing markets with strategies like deed restrictions that prevented minorities from accessing specific neighborhoods. The powers of HOAs include having the capability of requiring minimum credit scores in the mortgage market (Business insider, 2020).

Next, we turn to distinctions between the two platforms with respect to exclusionary criteria. As noted, a major difference between them is the lack of corporate landlords on Craigslist and their abundance on Zillow; we tallied 4212 listings (59\%) from a corporate entity. In general, the spatial patterns of Zillow mirror the overall listings combined, which largely reflects the high concentration of these corporate landlords in poorer and minority neighborhoods and who systematically include most restrictions as part of their automated screening processes. By comparison, Craigslist then tends to feature smaller or independent landlords, and consequently 
has some distinction in the spatial patterns of its exclusionary criteria. First, explicit restrictions on housing voucher holders from Craigslist advertisements are more common in higher-income neighborhoods, and second, restrictions on those with prior evictions are higher in Whiter neighborhoods; both are the opposite of what we observe from Zillow. It should be recognized that the share of listings that contained housing voucher restrictions on Craigslist was quite small (2\% of the sample). Like Zillow, minimum credit scores, minimum income, criminal background, and prior evictions were the most mentioned exclusionary criteria. The exclusionary criteria on Craigslist varies less systematically by race and income, given the few statistically significant relationships.

Table 2. Relationship between exclusionary criteria and share of White residents and median income by census tract. *Significant at $<=0.05$ 


\begin{tabular}{|c|c|c|c|c|c|c|c|}
\hline & $\begin{array}{l}\text { Criminal } \\
\text { Background }\end{array}$ & $\begin{array}{l}\text { Credit } \\
\text { Score }\end{array}$ & $\begin{array}{l}\text { Housing } \\
\text { Voucher }\end{array}$ & HOA & Evictions & $\begin{array}{l}\text { Minimum } \\
\text { Income }\end{array}$ & $\begin{array}{l}\text { All Terms } \\
\text { Combined }\end{array}$ \\
\hline \multicolumn{8}{|c|}{ All Listings } \\
\hline n (8616) & 4491 & 4811 & 137 & 929 & 4507 & 4585 & 19460 \\
\hline$\%$ White & $\begin{array}{l}-0.20 \\
p=0.00^{*}\end{array}$ & $\begin{array}{l}-0.17 \\
p=0.00^{*}\end{array}$ & $\begin{array}{l}-0.02 \\
p=0.05\end{array}$ & $\begin{array}{l}0.04 \\
p=0.07\end{array}$ & $\begin{array}{l}-0.19 \\
p=0.00 *\end{array}$ & $\begin{array}{l}-0.20 \\
p=0.00 *\end{array}$ & $\begin{array}{l}-0.75 \\
p=0.00^{*}\end{array}$ \\
\hline $\begin{array}{l}\text { Median } \\
\text { Income } \\
(\$ 1,000)\end{array}$ & $\begin{array}{l}-0.07 \\
p=0.05\end{array}$ & $\begin{array}{l}-0.06 \\
p=0.07\end{array}$ & $\begin{array}{l}0.000 \\
p=0.86\end{array}$ & $\begin{array}{l}0.06 \\
p=0.00^{*}\end{array}$ & $\begin{array}{l}-0.07 \\
p=0.06\end{array}$ & $\begin{array}{l}-0.07 \\
p=0.05\end{array}$ & $\begin{array}{l}-0.02 \\
p=0.16\end{array}$ \\
\hline \multicolumn{8}{|l|}{ Zillow } \\
\hline n (7174) & 3997 & 4265 & 125 & 915 & 4012 & 4072 & 17386 \\
\hline$\%$ White & $\begin{array}{l}-0.30 \\
p=0.00 *\end{array}$ & $\begin{array}{l}-0.25 \\
p=0.00 *\end{array}$ & $\begin{array}{l}-0.05 \\
p=0.00 *\end{array}$ & $\begin{array}{l}0.05 \\
p=0.07\end{array}$ & $\begin{array}{l}-0.29 \\
p=0.00^{*}\end{array}$ & $\begin{array}{l}-0.29 \\
p=0.00^{*}\end{array}$ & $\begin{array}{l}-1.12 \\
p=0.00^{*}\end{array}$ \\
\hline $\begin{array}{l}\text { Median } \\
\text { Income } \\
(\$ 1,000)\end{array}$ & $\begin{array}{l}-0.01 \\
p=0.01 *\end{array}$ & $\begin{array}{l}-0.09 \\
p=0.03 *\end{array}$ & $\begin{array}{l}-0.02 \\
p=0.00^{*}\end{array}$ & $\begin{array}{l}0.08 \\
p=0.00^{*}\end{array}$ & $\begin{array}{l}-0.11 \\
p=0.01 *\end{array}$ & $\begin{array}{l}-0.11 \\
p=0.00^{*}\end{array}$ & $\begin{array}{l}-0.37 \\
p=0.04 *\end{array}$ \\
\hline \multicolumn{8}{|l|}{ Craigslist } \\
\hline n (1442) & 494 & 546 & 12 & 14 & 495 & 513 & 2074 \\
\hline$\%$ White & $\begin{array}{l}0.13 \\
p=0.09\end{array}$ & $\begin{array}{l}0.09 \\
p=0.29\end{array}$ & $\begin{array}{l}-0.02 \\
p=0.44\end{array}$ & $\begin{array}{l}0.02 \\
p=0.10\end{array}$ & $\begin{array}{l}0.13 \\
p=0.01 *\end{array}$ & $\begin{array}{l}0.12 \\
p=0.12\end{array}$ & $\begin{array}{l}0.52 \\
p=0.11\end{array}$ \\
\hline $\begin{array}{l}\text { Median } \\
\text { Income } \\
(\$ 1,000)\end{array}$ & $\begin{array}{l}0.05 \\
p=0.37\end{array}$ & $\begin{array}{l}0.02 \\
p=0.80\end{array}$ & $\begin{array}{l}0.50 \\
p=0.00^{*}\end{array}$ & $\begin{array}{l}0.01 \\
p=0.12\end{array}$ & $\begin{array}{l}0.05 \\
p=0.40\end{array}$ & $\begin{array}{l}0.04 \\
p=0.42\end{array}$ & $\begin{array}{l}0.02 \\
p=0.325\end{array}$ \\
\hline
\end{tabular}

5. Discussion and Conclusions

Our analysis of spatial variations in exclusionary criteria from online rental listings obtained from Craigslist and Zillow affirms several themes that have recently emerged in the 
literature. First, our automated text analysis procedure based on a sample of web-scraped rental listings, yielded similar conclusions to those reached by Rosen et al.'s (2021) in-depth interviews of screening practices by landlords. We found that corporate landlords, who only advertised on Zillow, and not Craigslist, systematically included restrictions on minimum credit scores, incomes, criminal backgrounds, and prior evictions. As the share of holdings by these entities was larger in more minority and lower-income neighborhoods - an artifact of the housing market crash and disparities in predatory lending (Seymour \& Akers, 2021) - the concentration of these exclusionary criteria mentioned in listings followed. As mentioned by Rosen et al. (2021) and Decker (2021), the reliance on these legally observable, and seemingly objective traits for screening potential tenants enables larger, and often out-of-state landlords to skirt fair housing laws, but by using criteria that are largely correlated with race, they ultimately perpetuate longstanding patterns of inequity and segregation. By concentrating in minority and lowerincome neighborhoods where housing is typically more affordable, these exclusionary criteria could be a contributing factor to the rise in homelessness observed in a tight housing market such as Charlotte (Anderson \& Jarrett, 2021). The fact that corporate landlords do not advertise on Craigslist, which prior research has suggested is a clear source for more affordable rental housing opportunities (Costa et al., 2021; Hess et al., 2021), suggests that analyses of rental housing markets that exclusively rely on this platform may be missing a significant element of the rental landscape.

We also found some evidence that restrictions on housing choice voucher holders differ by platform - higher in wealthier neighborhoods on Craigslist, but more common in minority and poorer neighborhoods on Zillow. This could be explained by the notion that voucher holders have a greater stigma in higher-income neighborhoods and face greater restrictions by smaller 
landlords who rely more on 'gut' instincts than algorithmic proxies to screen applicants (Rosen et al., 2021; Decker, 2021). Corporate landlords did not systematically exclude voucher holders as was the case with minimum credit scores, incomes, prior evictions, or criminal background restrictions, but it is likely that most voucher holders would be excluded by minimum income requirements alone, which typically asked prospective renters for three times the monthly rent. Overall, the share of listings that contained explicit language barring voucher holders was quite limited. With a rise in corporate landlords nationally, this finding suggests that barring restrictions on housing voucher holders without tackling these other sources of categorical exclusion is unlikely to make a dent in the struggle for poor and minority residents, or those more likely to have discredited backgrounds, in securing housing.

We found listings with additional HOA requirements that often include further applications, fees, or background checks to be more common on Zillow (in 12\% of listings versus $<1 \%$ for Craigslist), and more frequent in higher-income neighborhoods. HOAs place an additional cost burden beyond the stated monthly rent and their presence in higher-income neighborhoods could exacerbate patterns of income segregation (Clarke \& Freedman, 2019).

Overall, when examining our sample of listings combined between Zillow and Craigslist, our results align with those of Besbris et al. (2021) who noted that the presence of exclusionary terms in rental listings in multiple large cities across the country was more common in poorer and minority neighborhoods. However, when we distinguish between the two platforms, our results indicate that this relationship no longer holds true - for Craigslist, we find no significant relationship in the collective presence of these terms with race and income, but for Zillow, our results are upheld. Additional probing of our data points to the significant influence of corporate landlords in explaining this finding - their dramatically increasing presence in poorer and 
minority neighborhoods, mechanisms for selecting tenants, and differences in online advertising may be quietly transforming the housing landscape. At a minimum, our results suggest the need for further analyses in other cities to determine the uniqueness of Charlotte with respect to these results, and importantly, the consequences to renters in securing housing.

In the case of Charlotte, source of income discrimination remains legal, and remedying this would be one solution. However, further addressing housing obstacles for those with other discredited backgrounds also needs to be resolved. An example of such policy can be found in Minneapolis' inclusive renter protection ordinance (Minneapolis City of Lakes 2019). Implementing such policies would improve accessibility to multiple housing options for lowincome households.

This research demonstrated a framework for evaluating online rental listings for exclusionary language - a method that may be more easily extensible to other study areas for comparisons that are less labor-intensive than in-depth interviews and surveys - though without the benefit of additional context. However, working with volunteered geographic information data from digital platforms such as Zillow and Craigslist also come with challenges. First, data from these digital platforms are only as good as the user's input. Hence, the data that was web scraped needed rigorous cleaning especially since we were dealing with unstructured data. User input that did not include the correct address meant that those listings could not be geocoded and included in our analysis. In instances where the address entered was correctly, but did not match the actual location of the listing, errors persisted in our analysis. Further, since we were web scraping rental listings from two platforms, we do not have the complete rental landscape picture for the city. Overall, however, the application of natural language processing to these data should offer housing 
policy researchers and planners valuable tools for monitoring discrimination in the local housing market.

\section{Acknowledgements}

The authors are grateful for the extremely constructive comments from the two anonymous reviewers who helped us improve this manuscript.

\section{References}

Anderson, B. \& Jarrett, E. (2021) Charlotte Mecklenburg State of Housing Instability and Homelessness Report. Charlotte Urban Institute. Retrieved from:

https://secureservercdn.net/50.62.172.157/275.2a4.myftpupload.com/wpcontent/uploads/2021/10/2021-Charlotte-Mecklenburg-State-of-Housing-InstabilityHomelessness-Report.pdf Last accessed 12/8/2021.

Besbris, M., Schachter, A., \& Kuk, J. (2021). The unequal availability of rental housing information across neighborhoods. Demography, 58(4), 1197-1221.

Boeing, G. (2020). Online rental housing market representation and the digital reproduction of urban inequality. Environment and Planning A: Economy and Space, 52(2), 449-468. 
Boeing, G., Besbris, M., Schachter, A., \& Kuk, J. (2021). Housing Search in the Age of Big Data: Smarter Cities or the Same Old Blind Spots?. Housing Policy Debate, 31(1), 112-126.

Boeing, G., \& Waddell, P. (2017). New insights into rental housing markets across the United States: Web scraping and analyzing craigslist rental listings. Journal of Planning Education and Research, 37(4), 457-476.

Brannon, M. M. (2017). Datafied and Divided: Techno-Dimensions of Inequality in American Cities.

Business Insider (2020) "When homeowners associations were first created, they helped keep Black people out of the neighborhood. They're still doing it today." Business Insider retrieved $(07 / 04 / 2021)$

Charlotte 2040 comprehensive plan (2020) "Charlotte Future” https://cltfuture2040.com/ retrieved $(07 / 072021)$

Childress Klein Center for Real Estate 2020 the state of housing in Charlotte report University of North Carolina at Charlotte (2020) "https://realestate.uncc.edu/research/state-housingcharlottereport” Retrieved (07/07/2021)

Clark, L. M. (2007). Landlord attitudes toward renting to released offenders. Fed. Probation, 71, 20.

Clarke, W., \& Freedman, M. (2019). The rise and effects of homeowners associations. Journal of Urban Economics, 112, 1-15.

Costa, A., Sass, V., Kennedy, I., Roy, R., Walter, R.J., Acolin, A., Crowder, K., Hess, C., Ramiller, A. and Chasins, S., (2021) Toward a Cross-Platform Framework. Cityscape, 23(2), pp.327-340.

Decker, N. (2021). How Landlords of Small Rental Properties Decide Who Gets Housed and Who Gets Evicted. Urban Affairs Review, 10780874211041513.

Delmelle, E., Nilsson, I., \& Adu, P. (2021). Poverty suburbanization, job accessibility, and employment outcomes. Social Inclusion, 9(2), 166.

Delmelle, E. C., \& Nilsson, I. (2021). The language of neighborhoods: A predictive-analytical framework based on property advertisement text and mortgage lending data. Computers, Environment and Urban Systems, 88, 101658.

DeLuca, S., Garboden, P. M., \& Rosenblatt, P. (2013). Segregating shelter: How housing policies shape the residential locations of low-income minority families. The ANNALS of the American Academy of Political and Social Science, 647(1), 268-299. 
Evans, D. N., Blount-Hill, K. L., \& Cubellis, M. A. (2019). Examining housing discrimination across race, gender and felony history. Housing Studies, 34(5), 761-778.

Fields, D. (2018). Constructing a new asset class: Property-led financial accumulation after the crisis. Economic Geography, 94(2), 118-140.

Freeman, L. (2012). The impact of source of income laws on voucher utilization. Housing Policy Debate, 22(2), 297-318.

Galster, G. C. (1992). Research on discrimination in housing and mortgage markets: Assessment and future directions. Housing Policy Debate, 3(2), 637-683.

Hanson, A., \& Hawley, Z. (2011). Do landlords discriminate in the rental housing market? Evidence from an internet field experiment in US cities. Journal of Urban Economics, 70(2-3), 99-114.

Hanson, A., \& Hawley, Z. (2014). Where does racial discrimination occur? An experimental analysis across neighborhood and housing unit characteristics. Regional Science and Urban Economics, 44, 94-106.

Hess, C., Acolin, A., Walter, R., Kennedy, I., Chasins, S., \& Crowder, K. (2021). Searching for housing in the digital age: Neighborhood representation on internet rental housing platforms across space, platform, and metropolitan segregation. Environment and Planning A: Economy and Space, 53(8), 2012-2032.

Hulchanski, J. D. (1994). Discrimination in Ontario's rental housing market: The role of minimum income criteria. Report prepared for the Ontario Human Rights Commission.

Kennedy, I., Hess, C., Paullada, A., \& Chasins, S. (2021). Racialized Discourse in Seattle Rental Ad Texts. Social Forces, 99(4), 1432-1456.

Krysan, M., \& Crowder, K. (2017). Cycle of segregation: Social processes and residential stratification. Russell Sage Foundation.

Langowski, J., Berman, W., Brittan, G., LaRaia, C., Lehmann, J. Y., \& Woods, J. (2020). Qualified Renters Need Not Apply: Race and Housing Voucher Discrimination in the Metropolitan Boston Rental Housing Market. Geo. J. on Poverty L. \& Pol'y, 28, 35.

Lindstrom, L. (2019) "Housing groups want to ban this 'unnecessary hurdle' for renters with vouchers" Charlotte Observer https://www.charlotteobserver.com/news/politicsgovernment/article238223029.html retrieved $(06 / 29 / 2021)$

Metzger, M. W. (2014). The reconcentration of poverty: Patterns of housing voucher use, 2000 to 2008. Housing Policy Debate, 24(3), 544-567. 
Minneapolis City of Lakes (2019) "Renter protections"

"https://www2.minneapolismn.gov/government/departments/reg-services/renter-protections/" retrieved $(07 / 02 / 2021)$

Oliveri, R. C. (2009). Discriminatory housing advertisements on-line: Lessons from Craigslist. Ind. L. Rev., 43, 1125.

Ondrich, J., Stricker, A., \& Yinger, J. (1999). Do landlords discriminate? The incidence and causes of racial discrimination in rental housing markets. Journal of Housing Economics, 8(3), 185-204.

Phelps, E. S. (1972). The statistical theory of racism and sexism. The American Economic Review, 62(4), 659-661.

Phillips, D. C. (2017). Landlords avoid tenants who pay with vouchers. Economics Letters, 151, 48-52.

Portillo, E. \& Lane, J. (2021) Wall street-backed landlords now own more than 11,000 single family homes in charlotte, UNC Charlotte Urban Institute https://ui.uncc.edu/story/wallstreetbacked-landlords-now-own-more-11000-single-family-homes-charlotte (retrieved $06 / 28 / 2021)$

Porton, A., Gromis, A., \& Desmond, M. (2020). Inaccuracies in eviction records: Implications for renters and researchers. Housing Policy Debate, 1-18.

Raymond, E. L., Duckworth, R., Miller, B., Lucas, M., \& Pokharel, S. (2016). Corporate landlords, institutional investors, and displacement: Eviction rates in single family rentals. FRB Atlanta community and economic development discussion paper, (2016-4).

Reosti, A. (2020). "We Go Totally Subjective": Discretion, Discrimination, and Tenant Screening in a Landlord's Market. Law \& Social Inquiry, 45(3), 618-657.

Reosti, A. (2021). The Costs of Seeking Shelter for Renters With Discrediting Background Records. City \& Community, 15356841211012483.

Rosen, E. (2014). Rigging the Rules of the Game: How Landlords Geographically Sort LowIncome Renters. City \& Community, 13(4), 310-340.

Rosen, E., Garboden, P. M., \& Cossyleon, J. E. (2021). Racial Discrimination in Housing: How Landlords Use Algorithms and Home Visits to Screen Tenants. American Sociological Review, 86(5), 787-822.

Schwemm, R. G. (2006). Why do landlords still discriminate (and what can be done about it). J. Marshall L. Rev., 40, 455. 
Seymour, E., \& Akers, J. (2021). Building the eviction economy: Speculation, precarity, and eviction in Detroit. Urban Affairs Review, 57(1), 35-69.

Strahilevitz, L. J. (2006). Exclusionary amenities in residential communities. Va. L. Rev., 92, 437.

Tighe, J. R., Hatch, M. E., \& Mead, J. (2017). Source of income discrimination and fair housing policy. Journal of Planning Literature, 32(1), 3-15.

U.S. Census Bureau (2019). Charlotte City Profile, 2015-2019 American Community Survey 5year estimates retrieved from https://data.census.gov/cedsci/profile?g=1600000US3712000 $(07 / 07 / 2021)$

\section{Notes on Contributors}

Providence Adu is a PhD student in the department of Geography and Earth Sciences at the University of North Carolina at Charlotte. E-mail: padu@uncc.edu He is also a research assistant at the UNC Charlotte Urban Institute and a former urban planner for the city of Charlotte. His research interests include housing, neighborhood change, and the role of government in spurring changes. He uses quantitative methods and machine learning in his work. 
Elizabeth C. Delmelle is an Associate Professor in the department of Geography and Earth Sciences at the University of North Carolina at Charlotte. E-mail: edelmell @ uncc.edu Her research falls at the intersection of urban and transportation geography and GIScience, most notably in understanding processes of neighborhood change, residential sorting, and location choice. 